\title{
South Shore Clean Cities - Increasing Environmental Benefits through Reduction
}

\author{
Joseph Trendowski \\ Valparaiso University \\ Stephanie Trendowski \\ Valparaiso University
}

For nearly twenty years, Carl and Lorrie Lisek have been making the Lake Michigan Region a greener place. As entrepreneurs, they consciously work toward their mission of leaving the world a better place for their children. South Shore Clean Cities collaborates with a variety of programs and institutions to "revitalize Northern Indiana by promoting the use of clean fuels and clean vehicle technologies". They strongly believe in improving air quality, developing economic opportunities and reducing the use of imported oil. As their success continues, South Shore Clean Cities has an opportunity to further its impact on the region and the globe.

\section{LEARNING OBJECTIVES}

The objectives of the South Shore Clean Cities case are:

1. Students will determine the effectiveness of the programs that SSCC has implemented.

2. Students will evaluate the effectiveness of environmental programs in their home area.

3. Students will discuss future opportunities where SSCC can make a difference.

\section{APPLICATION}

The South Shore Clean Cities Case is appropriate for undergraduate business students. Courses in management, organizational behavior, and ethics would be logical classes to maximize the value of the case.

\section{INTRODUCTION}

Clean air. Clean water. Clean food. South Shore Cleans Cities co-founder Carl Lisek uses those three sentences to describe what all people desire. Nearly 20 years ago, he and his wife Lorrie decided they wanted to start something that would make the world a better place, so they put their expertise and their savings into launching Legacy Environmental. Over the course of two decades, Carl and Lorrie have seen fantastic progress and growth in the area of sustainability, but also realize there is a tremendous amount that still could be done. 
South Shore Clean Cities, Inc. (SSCC) operates as a non-profit 501(3)c. It is one of nearly 100 active U.S. Department of Energy (DOE) Clean Cities Coalitions in the United States. One of the main purposes of these coalitions is to utilize the advancing alternative fuels, idle reduction technology, hybrid electric vehicles and fuel economy. Carl and Lorrie founded South Shore Clean Cities, in 1999, strongly believing that individuals working together towards common goals will be able to further the nation's objectives of improved air quality, developing economic opportunities and reducing the use of imported oil.

Their mission is "to preserve and revitalize Northern Indiana by promoting the use of clean fuels and clean vehicle technologies". They currently operate in 18 Northern Indiana counties, including Lake, Porter, LaPorte, St. Joseph, Elkhart, LaGrange, Steuben, Newton, Jasper, Starke, Marshall, Kosciusko, Noble, DeKalb, Pulaski, Fulton, Whitley, and Benton County. In order to fulfil its mission, South Shore Clean Cities employs education and outreach, training, and stakeholder partnership. As part of the loosely constituted Lake Michigan Clean Cities Consortium, South Shore Clean Cities partners in educational events and special conferences with Wisconsin Clean Cities and Chicago Area Clean Cities.

\section{CLEAN CITIES}

Clean Cities was an industry partnership sponsored by the United States Department of Energy to reduce petroleum consumption in the transportation sector. With the passage of the Energy Policy Act of 1992 (EPAct), certain vehicle fleets were encourages to use alternative fuel vehicles. As a result, the department of energy developed Clean Cities to provide "informational, technical, and financial resources to EPAct-regulated fleets and voluntary adopters of alternative fuels and vehicles." Since its inception in 1993, Clean Cities has saved more than 7.5 million gallons of petroleum.

Clean Cities is a government/industry partnership designed to reduce petroleum consumption in the transportation sector by advancing the use of alternative fuels and vehicles, idle reduction technologies, hybrid electric vehicles, fuel blends and fuel economy. Sponsored by the U.S. Department of Energy, Clean Cities contributes to the environmental, economic and energy security of our nation by reducing our dependence on imported petroleum. To learn more, visit the Clean Cities website at https://cleancities.energy.gov/.

Nationally, Clean Cities develops and promotes partnerships, publications, tools and other inimitable resources. Locally, South Shore Clean Cities leverages these resources to create networks of stakeholders and provide knowledge and technical advice to fleets and energy users in implementing alternative and renewable projects. South Shore Clean Cities activities include building partnerships with local coalitions of public and private-sector stakeholders, developing information resources about alternative fuels, alternative energies, advanced vehicles and other strategies to cut petroleum and energy use. 


\section{CLEAN CITIES ACTIVITIES}

- Building partnerships with local coalitions of public- and private-sector transportation stakeholders

- Developing unbiased and objective information resources about alternative fuels, advanced vehicles, and other strategies to cut petroleum use

- Advancing interactive, data-driven online tools to help stakeholders evaluate options and achieve goals

- Collecting and sharing best practices, data, and lessons learned to inform choices and build a strong national network

- Providing technical assistance to help fleets deploy alternative fuels, advanced vehicles, and idle-reduction measures

- Working with industry partners and fleets to identify and address technology barriers

- Empowering local decision makers to successfully implement the best petroleum reduction strategy for their circumstance

- Seeding local alternative fuels markets through projects that deploy vehicles and fueling infrastructure.

Source: cleancities.energy.gov

\section{LAKE MICHIGAN CORRIDOR}

Currently, South Shore Clean Cities is an active member of The Lake Michigan Corridor Alternative Fuel Implementation Initiative. This two-year regional project is designed to determine barriers to the implementation of CNG, propane and electric vehicle fuels. The Lake Michigan Corridor is home to nearly 10 million people. South Shore Clean Cities, Chicago Area Clean Cities, Wisconsin Clean, along with the Gas Technology Institute are providing research assistance in the region. Together, the group established alternative fuel corridors along I-90 and I-94, as well as created alt-fuel hot spots in Chicago, Milwaukee, and Gary and South Bend, Indiana. The project, now encompassing 500 participants, addresses policies, barrier reduction, safety and training and market development. They share information in the areas of alternative fuel stations, inspection criteria, success of alternative fuel programs, success of green purchasing policies, and educational materials among other things.

\section{SMARTWAY PROGRAM}

South Shore Clean Cities is at the forefront of clean fleet management with the US EPA SmartWay Program and the Northwest Indiana Green Fleet Program. SmartWay provides incentives to fleets to improve their supply chain fuel efficiency. As fleets often contain several dozen vehicles, or more, the reduction of transportation related emissions is immense. While partnering with local trucking and transportation companies, South Shore Clean Cities promotes idle reduction and fuel efficiency methods and technologies to contribute to the overall mission of accelerating the availability, adoption, and market penetration of advanced fuel efficiency technology. They help partner companies move more goods, more miles while using less energy and outputting lower emissions. South Shore Clean Cities further instills this practice through the Northwest Indiana Green Fleet Program. Utilizing the same principles, South Shore Clean Cities has collaborated with local governments (Lake, Porter, and LaPorte County Indiana) to improve their government vehicle performance. 


\section{EXPANDING OUTSIDE ALTERNATIVE FUELS}

Taking the efficiency program home, literally, South Shore Clean Cities has partnered with the local utility company, NIPSCO. As part of the in-charge electric vehicle program, they support this unique opportunity as the direct point-of contact program managers. NIPSCO customers are able to receive a credit of up to $\$ 1,650$ for installing an in-home charging station. This opportunity provides a new outlet for Carl and Lorrie Lisek to improve environmental conditions in the Lake Michigan region.

\section{FUTURE OPPORTUNITIES}

Over the past two decades Carl and Lorrie Lisek have had a profound impact on the Lake Michigan Region. Their efforts were recognized by being inducted into the Department of Energy Clean Cities Hall of Fame. With their continued success and intense motivation, Carl, Lorrie, and their South Shore Clean Cities are continuously on the lookout for new opportunities to make a difference. Whether it involves bringing new members into existing programs or developing entire new ones, Carl and Lorrie Lisek have sustainability on their mind at all times. As we move further in the direction of societal focus on these programs, the tremendous impact of South Shore Clean Cities will likely create new avenues to foster a greener region.

\section{POTENTIAL EPA CUT}

Prior to the 2016 presidential election, Carl was confident that the United States push towards sustainability would continue regardless of who was elected. In the past, he experienced bi-partisan support towards South Shore Clean Cities and its mission. In the wake of the election, a discussion developed about cutting federal programs, including the EPA. As of March 2017, proposed budget cuts would slash the EPA budget by as much as $31 \%$. The budget includes programs that study pollution and environmental toxins and write laws for enforcement. Clean air, clean water, and climate change programs were specifically highlighted as programs that would endure most of the cuts ${ }^{1}$.

\section{TEACHING NOTE}

\section{CASE QUESTIONS:}

1. Describe the impact that South Shore Clean Cities has had on the region?

2. Who is SSCC collaborating with and how has that collaboration helped move their mission forward?

3. Given the successes that SSCC has already achieved, where is the next opportunity that they can make a difference?

4. What are sustainability programs under way in your local communities? How do they compare to what SSCC is doing?

5. How will potential EPA cuts affect SSCC in fulfilling their mission?

\section{CASE DESCRIPTION}

The primary subject matter of this case concerns South Shore Clean Cities role in making the Lake Michigan Corridor a more environmentally friendly place. The secondary issues examined include the impact of changing regulations at the national level and finding new ways to spread your mission. The case has a difficulty level of three; junior level. This case is designed to be to be taught in one to one and a half hours and is expected to require one hour of outside preparation by students. 


\section{CASE SYNOPSIS}

For nearly twenty years, Carl and Lorrie Lisek have been making the Lake Michigan Region a greener place. As entrepreneurs, they consciously work toward their mission of leaving the world a better place for their children. South Shore Clean Cities collaborates with a variety of programs and institutions to "revitalize Northern Indiana by promoting the use of clean fuels and clean vehicle technologies". They strongly believe in improving air quality, developing economic opportunities and reducing the use of imported oil. As their success continues, South Shore Clean Cities has an opportunity to further its impact on the region and the globe.

\section{RECOMMENDATION FOR TEACHING APPROACH}

For initial discussion, ask the students how many of them are interested in having clean air, clean water, and clean food (As mentioned in the case by Carl). In general, students usually unanimously agree that those items are important. The next point is to discuss the alternative - such as not having those things. More specifically, what would the absence of clean air, water, and food mean to the student. Typically, this starts a very strong discussion in the area of sustainability. Students will generally have a strong feeling on their views in this field, which also may include recommendations. The potentially could begin a debate on the balance and government intervention.

Begin the discussion with big picture question and then move down to the more case specific ones. This provides the students and opportunity to share and discuss their own perspectives in the area of green initiatives and sustainability. One big picture question coincides well with the first case question Describe the impact South Shore Clean Cities has had on the region? Students answering this question are not limited by the case itself. There will be answers that students discuss that will have both direct and indirect implications. This type of question to be a strong starting point. Once the student has formed her or her own perspective on the topic, the subsequent questions will have much more engaging responses. Continue to engage the students with the following assigned case questions.

Specifically, to the case, there are some additional questions that may be useful for class discussion:

\section{CASE QUESTION DISCUSSION:}

1. Describe the impact that South Shore Clean Cities has had on the region?

As discussed in the teaching approach, this is a question to ask early in the discussion. Students will all have their own idea of what impact is, and how SSCC is able create impact. Those that are familiar with Lake Michigan and the surrounding area may discuss the areas relevance in the steel industry. Traditionally, the steel industry has not been the most environmentally friendly. Companies like SSCC, are working with these industries to keep their important economic impact while reducing their environmental impact. Student may also indicate that the region is home to several large urban areas, including Chicago and Milwaukee. Due to a large number of people living in a relatively small confined space leads to potentially harmful environmental outcomes. Carl and Lorrie specifically highlight clean air, clean water and clean food as a major goal of theirs which is essential to the 10 million people living in the region. Further, SSCC has partnered with other organizations both locally and nationally to further their mission. In their infancy, there was little emphasis on their programs. As they have grown, so has the passion for what they are doing. It can be argued that SSCC has organically developed passion in the region for sustainability.

2. Who is SSCC collaborating with and how has that collaboration helped move their mission forward?

Building off the first question, the second question asks for details from the case. The first major partnership to discuss is the National Clean Cities partnership. Clean Cities provides informational, technical, and financial resources to EPA regulated fleets and voluntary adopters of alternative fuels and vehicles. As part of this national partnership, they are able to impact millions of individuals locally and nationally with the help of other Clean Cities programs. Secondly, they are working specifically with other local clean cities in Illinois, Indiana, Michigan, and Wisconsin to collaborate with the Gas 
Technology Institute to determine the barriers to implementation of compressed natural gas (CNG), and electric vehicles. They have created alternative fuel hot spots in Chicago, Milwaukee, Gary, and South Bend. Third, they have been leading the way with the Northwest Indiana Green Fleet program and SmartWay program. SSCC partners with local companies to help them move more goods, more miles, while using less energy and emitted less emissions.

Each of these partnerships might be discussed in terms of how the collaborative efforts of many have a great impact than one singular unit alone.

3. Given the successes that SSCC has already achieved, where is the next opportunity that they can make a difference?

This question relies on the student's creativity and passion for making a difference. This is the type of open ended question that gets students to think critically. They may start their conversation on what SSCC is currently doing and then tie that into synergies for the future. A variety of different approaches may be taken. First, a student may look at the portfolio of SSCC and suggest other projects to add into it. Second, a student may notice external strategic partners that SSCC may begin a relationship with. Third, a student may discuss geographic expansion so that SSCC may reach more people. Fourth, a student may consider international expansion, especially to regions/locations that are less environmentally friendly. These four are only a few suggestions as the answers are only limited by the student's creativity. This should provide and excellent discussion.

4. What sustainability programs are under way in your local communities? How do they compare to what SSCC is doing?

Students who have experience in this area will likely be the ones leading the discussion. This is extremely beneficial for others who may not be as well versed in the area. It is an eye-opening conversation that gets students to think about what's happening behind the scenes. If students are struggling to think of what is being done locally, ask them to think about what is happening on campus. Most colleges and university has made a conscious effort to be more green/sustainable. This can start with something as small as recycling and continue into discussion of more energy efficient buildings and/or processes. It is very likely there is evidence of these programs everywhere.

5. How will potential EPA cuts affect SSCC in fulfilling their mission?

The quick answer is less money equals fewer opportunities. SSCC may have to shrink the number of programs and become more focused on a few. The more detailed answer would include how SSCC may be able to stench their budget or find other ways to make an impact. It should also be noted that this is speculation at this point (though it may not be at the time of the case). As budgets are constantly evolving, the most impactful discussion on this topic will occur in the present. In short, given what we know now, what can SSCC do?

\section{ENDNOTES}

1. http://www.cnbc.com/2017/03/16/white-house-seeks-to-cut-epa-budget-31-as-trump-targetsregulation.html 